\title{
PENGARUH PEMBUMIAN KAKI TOWER TERHADAP PERKIRAAN OUTAGE RATE SALURAN UDARA 150 KV SAAT TERJADI SAMBARAN PETIR
}

\author{
Brian Bramantyo S.D.A. Harsono ${ }^{1)}$ dan Istiqomah $^{2}$ \\ ${ }^{1,2}$ PT PLN (Persero) Pusat Penelitian dan Pengembangan Ketenagalistrikan \\ Email: brian.adiputro@pln.co.id ${ }^{1)}$ \\ Nomor Telp : +62 8179881162 \\ Asal Negara: Indonesia
}

\begin{abstract}
ABSTRAK
Tingginya kerapatan petir yang ada di Indonesia mendorong pentingnya dilakukan peningkatan unjuk kerja Saluran Udara Tegangan Tinggi (SUTT) terhadap sambaran petir. Sebagai salah satu upaya preventif maintenance, PLN telah melakukan pengukuran tahanan pembumian tower SUTT secara periodis. Makalah ini bertujuan untuk mengetahui pengaruh nilai tahanan pembumian tower SUTT terhadap total outage rate dari saluran serta melakukan review terhadap metode pengukuran tahanan pembumian yang digunakan. Tahapan penelitian ini terdiri dari: a) pengumpulan data karakteristik petir di sepanjang rute saluran, b) pemodelan saluran transmisi udara, c) simulasi perkiraan outage rate dengan variasi kondisi pembumian, dan d) evaluasi standar terkait dengan metode pengukuran pembumian tower. Berdasarkan simulasi menggunakan TFlash untuk data karakteristik petir dan geometri saluran yang diperoleh, maka diketahui perkiraan outage rate SUTT sebesar 15,77 flashover/100 km/tahun yang terdiri dari 12,77 kejadian back flashover dan 3,00 kejadian flashover akibat shielding failure. Berdasarkan hasil evaluasi dan analisis data, diketahui kenaikan tahanan pembumian tower sebesar 6 kali dapat menyebabkan kenaikkan total outage rate dari saluran udara sebesar 129,93\%. Hal tersebut mendorong perlunya dilakukan pemantauan nilai tahanan pembumian secara teratur dengan menggunakan metode yang sesuai dengan standar yang berlaku. Khusus untuk tower dengan ground rod yang tidak dapat dipisahkan dari struktur tower, maka perlu dipertimbangkan pengukuran menggunakan metode Fall out Potential/FoP dan pengukuran arus bocor.
\end{abstract}

Kata kunci: Karakterisasi petir, kerapatan petir, saluran udara, pemodelan, BIL

\section{ABSTRACT}

High ground flash density characteristic in Indonesia drives the needs to improve overhead transmission line performance toward lightning strike. As a part of predictive maintenance, PLN performs tower resistance measurement in periodic time frame. This paper aims to determine the effect of overhead transmission line $(O H L)$ tower footing resistance toward its total outage rate and to review a suitable method for measuring footing resistance based on related standards. Several research steps were conducted, including: a) identifying lightning characteristics along the OHL route, b) OHL modeling, c) outage rate simulation for each tower footing resistance value, and d) evaluating related standard to find suitable footing resistance measurement method. According to the simulation using TFlash, the total outage rate of the evaluated OHL was 15,77 flashover/100 $\mathrm{km} /$ year which consist of 12,77 flashovers due to back flashover and 3,00 flashovers due to shielding failure. Based on the data evaluation and analysis, the increase of tower footing resistance up to 6 times will give an increase to total outage rate 129,93\%. This finding emphasizes the importance of measuring footing resistance regularly with the proper method. For OHL with welded ground rods, tower footing resistance measurement using Fall out Potential and leakage current measurement method is advised.

Keywords: lightning characteristic, lightning density, overhead transmission line, model, BIL

\section{PENDAHULUAN}

Kerapatan petir merupakan salah satu parameter yang harus dipertimbangkan dalam penentuan rencana jalur saluran udara tegangan tinggi/SUTT (Committee 1997). Hal tersebut berkaitan dengan besarnya nilai flash collection rate dari SUTT, dimana kerapatan petir yang semakin tinggi akan menyebabkan nilai flash collection rate menjadi semakin tinggi. Berdasarkan peta petir yang dinyatakan pada Gambar 1 (Holle and Brooks 2019), dapat diketahui bahwa Indonesia memiliki karakteristik kerapatan petir yang lebih tinggi dibandingkan negara lain. Dengan demikian, besarnya nilai flash collection rate dari SUTT milik PT PLN (Persero) cenderung lebih tinggi dibandingkan SUTT milik utilitas ketenagalistrikan di negara lain. Dokumen Evaluasi Operasi Tahunan periode 2015 - 2020 menunjukkan bahwa sambaran petir masih menjadi penyebab dominan gangguan SUTT milik PLN. Untuk menjaga kehandalan SUTT 
yang berada di daerah dengan paparan petir cukup tinggi, pertimbangan terkait karakteristik petir sangat diperlukan dalam tahapan desain termasuk pola pemeliharaan dari SUTT.

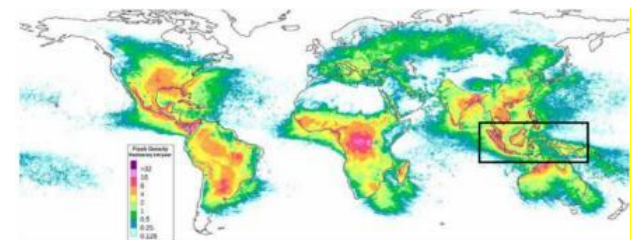

Gambar 1. Peta kerapatan petir dunia untuk periode 2014-2018 (Holle and Brooks 2019)

Sesuai dengan fungsinya untuk mengalirkan daya dari pembangkit ke gardu induk, SUTT dapat dibagi menjadi dua subsistem: subsistem primer (rangkaian pembawa arus, insulasi, struktur, dan sambungan) dan subsistem sekunder (proteksi petir dan sarana monitoring). Menurut referensi (Thottappillil and Theethayiz 2009), sistem proteksi petir berfungsi untuk melindungi struktur termasuk perlengkapan dan personel yang ada di dalam/di dekatnya dari sambaran petir. Proteksi petir tersusun atas 3 komponen utama, yaitu: a) air terminal untuk melindungi struktur dari sambaran petir langsung, b) jalur/saluran pembumian untuk meneruskan arus petir dari air terminal ke terminal pembumian, dan c) terminal pembumian untuk membuang arus petir ke bumi. Untuk menjaga fungsi dari 3 komponen utama proteksi petir tersebut, proses pemeliharaan yang tepat perlu dilakukan oleh PLN secara periodik. Fungsi utama dari proses pemeliharaan adalah untuk memastikan suatu peralatan dapat beroperasi sesuai dengan desain awalnya. Mengacu pada standar pemeliharaan yang ada di PLN, pemeliharaan SUTT dibagi menjadi 3 bagian yaitu: a) pemeliharaan preventif, b) pemeliharaan pasca gangguan, dan c) pemeliharaan korektif. Pemeliharaan preventif bertujuan untuk mencegah terjadinya kerusakan peralatan pada melalui kegiatan pemeliharaan rutin (in service visual inspection, ground patrol, dan climb up inspection), pemeliharaan prediktif saat bertegangan (contohnya: uji thermovisi, pengukuran jarak, pengujian puncture, pengujian resistansi pentanahan, dan pengambilan data transmission line arrester/TLA), dan pemeliharaan prediktif saat tidak bertegangan. Terkait dengan pengukuran tahanan pembumian, metode pengukuran yang digunakan adalah Fall out Potential/FoP dengan catatan ground rod dapat dipisahkan dari struktur tower. Pada operasional di lapangan, hampir sebagian besar ground rod pembumian tower dilas dengan struktur sehingga tidak dapat dilepas. Hal tersebut dapat berpotensi menyebabkan metode FoP yang digunakan tidak dapat menggambarkan kondisi tahanan pembumian yang sebenarnya. Penelitian ini dibuat bertujuan untuk mengetahui hubungan nilai pembumian kaki tower dengan perkiraan outage rate dari saluran transmisi khususnya pada saat terjadi kenaikan tahanan pembumian yang tidak diketahui akibat metode pengukuran yang tidak tepat. Selain itu, review terkait standar pengukuran pembumian juga dilakukan untuk memberikan gambaran metode yang tepat untuk kondisi ground rod yang tidak dapat dilepaskan dari struktur tower.

\section{METODE}

Untuk mengetahui dampak nilai tahanan pembumian pada perkiraan outage rate dari saluran transmisi, maka perlu dilakukan pengambilan 3 data primer meliputi: a) data kejadian petir di sepanjang saluran, b) data desain saluran pada saat pembangunan/as built drawing, dan c) metode pengukuran pembumian tower saat saluran tersebut beroperasi (Gambar 2). Data kejadian petir dan data desain saluran digunakan dalam perhitungan perkiraan outage saluran, sementara perbandingan metode pengukuran pembumian yang digunakan saat ini terhadap referensi standar lain yang terkait dilakukan untuk memberikan masukan bagi sisi pemeliharaan. Variasi nilai pembumian dilakukan pada perhitungan perkiraan total outage rate sebagai masukan dalam pengambilan keputusan pada tahapan operasional saluran.

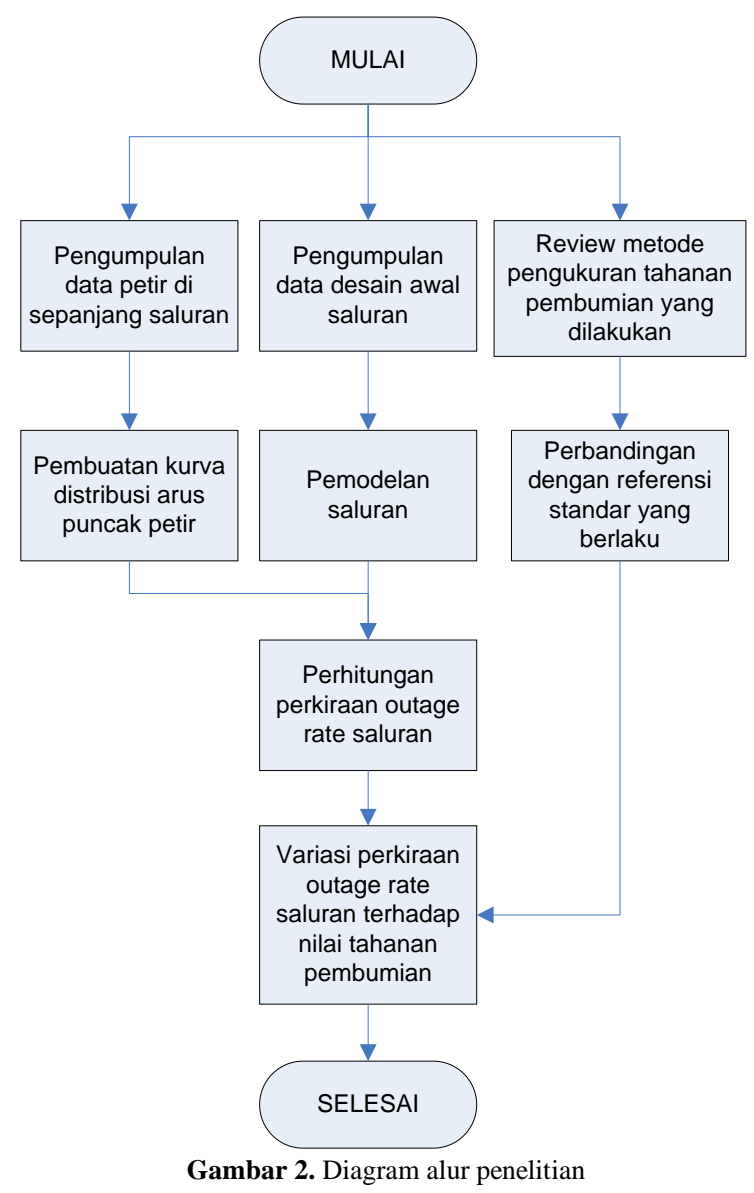

Secara detail, tahapan yang dilakukan dalam penelitian ini dapat dinyatakan sebagai berikut: a) pengumpulan data karakteristik petir di sepanjang 
rute saluran, b) pemodelan saluran transmisi udara, c) simulasi perkiraan outage rate dengan variasi kondisi pembumian, dan d) evaluasi standar terkait dengan metode pengukuran pembumian tower. Rekam data petir yang digunakan diperoleh dari sistem deteksi petir PLN untuk periode pengukuran 2018 - 2020, khususnya untuk data return stroke yang pertama. Data tersebut diolah untuk mendapatkan distribusi kejadian petir kumulatif sambaran petir untuk masing-masing nilai arus puncak. Pemodelan SUTT $150 \mathrm{kV}$ dilakukan dengan menggunakan perangkat lunak TFlash yang dibuat oleh EPRI dengan input data berupa: data geometri tower, data dimensi kawat fasa dan kawat pembumian, nilai critical flashover/CFO dari isolator yang digunakan, dan data nilai pembumian dari kaki tower. Berdasarkan data distribusi kejadian petir kumulatif dan pemodelan saluran yang diperoleh, perkiraan outage rate saluran dapat dihitung berdasarkan pendekatan shielding failure flashover outage rate/SFFOR dan back flashover outage rate/BFOR yang dinyatakan dalam IEEE (Thottappillil and Theethayiz 2009). Variasi kondisi pembumian kaki tower yang dilakukan berfokus pada perubahan nilai tahanan pembumian SUTT untuk mengetahui perubahan outage rate yang terjadi. Review metode pengukuran pembumian dilakukan dengan mengacu pada IEEE (IEEE Std 81 2012), khususnya untuk metode FoP dan metode FoP yang dilengkapi pengukuran arus bocor. Contoh perbandingan hasil pengukuran di antara kedua metode tersebut disajikan untuk memberikan gambaran lebih lanjut dari dua metode yang dievaluasi.

\section{HASIL DAN PEMBAHASAN}

\subsection{Karakteristik Petir}

Rekam data petir dari saluran $150 \mathrm{kV}$ di daerah Jawa Barat untuk periode 2018-2020 diolah menjadi grafik distribusi kejadian kumulatif sambaran petir seperti yang dinyatakan pada Gambar 3. Apabila dibandingkan dengan hasil survey sebaran nilai arus puncak yang dilakukan oleh CIGRE dan IEEE (Martínez Velasco et al. 2018), dapat diketahui bahwa karakteristik sambaran petir pada saluran 150 $\mathrm{kV}$ yang digunakan mendekati kurva CIGRE $( \pm 50 \%$ kumulatif sambaran petir memiliki nilai puncak 25 kA). Nilai 50\% kumulatif sambaran petir tersebut menyerupai kondisi di negara lain seperti Australia yang berkisar $21 \mathrm{kA}$ (Nampak et al. 2021) atau di Amerika yang berkisar 23,1 kA (Cummins, Wilson, and Eichenbaum 2019).

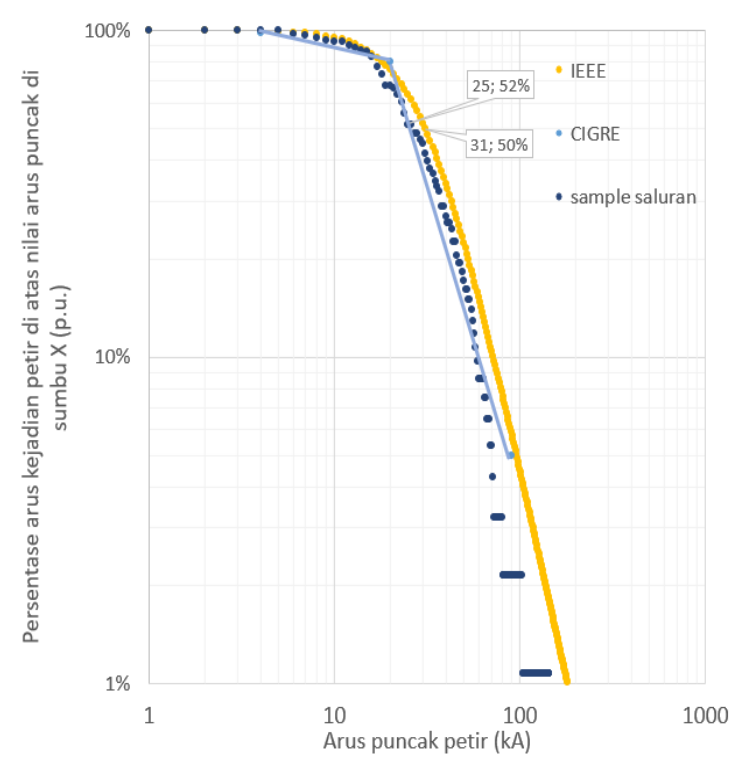

Gambar 3. Kejadian kumulatif sambaran petir untuk jalur saluran $150 \mathrm{kV}$ dibandingkan dengan kurva CIGRE dan IEEE

Pemetaan rekam data petir pada jalur saluran udara yang digunakan (grid $5 \mathrm{~km} \quad \mathrm{x} \quad 5 \quad \mathrm{~km}$ ) menunjukkan nilai rata-rata ground flash density/GFD tertinggi mencapai 24,20 sambaran/km2/tahun. Nilai kerapatan petir tersebut lebih tinggi dibandingkan kerapatan petir di daerah Eropa yang berkisar 0,1-4 sambaran $/ \mathrm{km} 2 /$ tahun maupun di Amerika yang berkisar 14 sambaran/km2/tahun (Holle and Cummins 2010; Javor et al. 2018). Meskipun demikian, perlu menjadi catatan bahwa karakteristik kejadian kumulatif maupun GFD tersebut dapat berbeda untuk rute jalur/daerah yang lainnya.

\subsection{Pemodelan Saluran Udara}

Parameter tower dan saluran eksisting yang digunakan dalam penelitian ini dinyatakan pada Gambar 4 dan Tabel 1.

Tabel 1.

Parameter tower eksisting

\begin{tabular}{ccc}
\hline Parameter & Nilai & Satuan \\
\hline Sag konduktor & 8 & $\mathrm{~m}$ \\
Sag GSW & 7 & $\mathrm{~m}$ \\
Diameter ACSR & 2,896 & $\mathrm{~cm}$ \\
Jumlah konduktor & 1 & - \\
Diameter GSW & 0,914 & $\mathrm{~cm}$ \\
Tahanan pembumian & 5 & $\Omega$ \\
Jumlah insulator & 12 & piring \\
CFO insulator & 1060 & $\mathrm{kV}$ \\
\hline
\end{tabular}




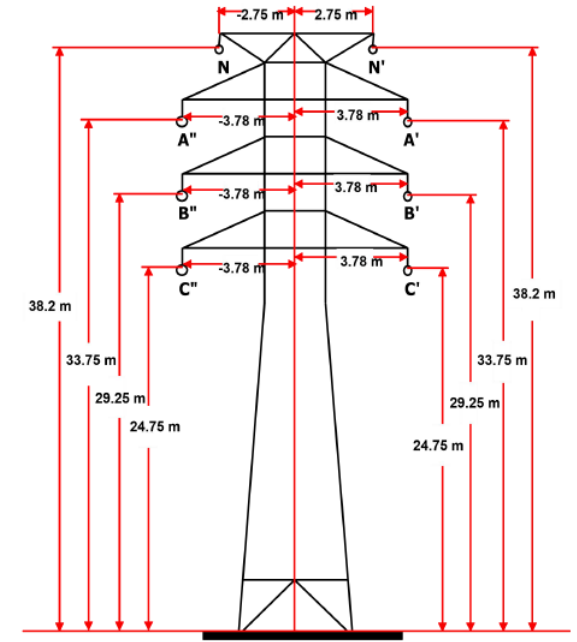

Gambar 4. Desain Tower $150 \mathrm{kV}$ yang digunakan

Petir dengan nilai arus puncak di atas $15 \mathrm{kA}$ akan cenderung menyambar pada kawat pembumian/ground steel wire (GSW) seperti yang ditunjukkan pada Gambar 5. Besarnya nilai kenaikan tegangan yang terjadi saat petir $15 \mathrm{kA}$ menyambar kawat fasa adalah sebesar $2800 \mathrm{kV}$ (Gambar 6). Berdasarkan simulasi sambaran pada GSW, dapat diketahui bahwa petir dengan nilai arus puncak -47 kA dapat menyebabkan kenaikan tegangan hingga $1089 \mathrm{kV}$ yang melebihi nilai CFO dari insulator yang digunakan (Gambar 7). Saat nilai CFO insulator terlampaui (akibat sambaran pada kawat fasa maupun sambaran pada GSW), maka akan terjadi flashover pada insulator yang menyebabkan gangguan fasa ke bumi pada SUTT. Kejadian flashover tersebut menjadi dasar perhitungan perkiraan outage rate dari saluran (Martínez Velasco, Corea Araujo, and Bedoui 2018; Mikropoulos and Tsovilis 2017; Shafaei, Gholami, and Shariatinasab 2012)

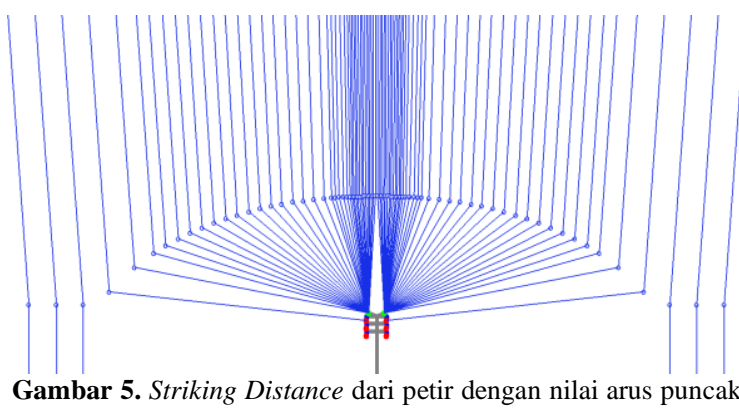
$-15 \mathrm{kA}$

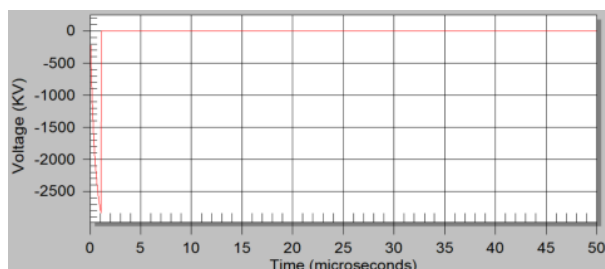

Gambar 6. Kenaikan tegangan pada insulator fasa atas saat terjadi sambaran petir dengan nilai arus puncak $-15 \mathrm{kA}$ ke kawat fasa teratas

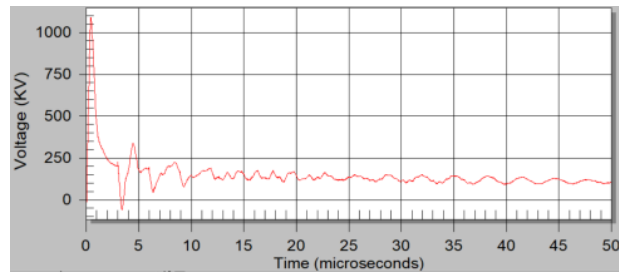

Gambar 7. Kenaikan tegangan pada insulator fasa atas saat terjadi sambaran petir dengan nilai arus puncak petir $-47 \mathrm{kA}$ ke GSW

\subsection{Perkiraan Outage Rate untuk Variasi Nilai Pembumian Kaki Tower}

Berdasarkan simulasi TFlash untuk data karakteristik petir dan geometri saluran yang diperoleh, dapat diketahui perkiraan outage rate sebesar 15,77 flashover/100 km/tahun yang terdiri dari 12,77 kejadian back flashover dan 3,00 kejadian flashover akibat shielding failure. Kejadian BFOR lebih banyak dibandingkan SFFOR karena radius sambar dari petir berbanding lurus dengan besarnya nilai arus puncak: semakin tinggi nilai arus puncak, maka striking distance makin besar. Berdasarkan sub bab 3.2, diketahui bahwa petir dengan nilai arus puncak $\leq-15 \mathrm{kA}$ akan menyambar kawat fasa sementara petir dengan nilai $>15 \mathrm{kA}$ akan menyambar GSW. Kejadian petir dengan nilai arus puncak $15 \mathrm{kA}$ berkisar 10\% (Gambar 2), sehingga kemungkinan terjadinya sambaran ke kawat fasa lebih kecil dibandingkan sambaran ke GSW. Hal tersebut menyebabkan kemungkinan SFFOR menjadi lebih kecil dibandingkan BFOR. Perhitungan BFOR dipengaruhi oleh GFD serta probabilitas kejadian arus puncak petir yang menyebabkan kenaikan tegangan tower melebihi CFO dari insulator (Martínez Velasco et al. 2018). Tahanan pembumian tower berpengaruh pada kenaikan tegangan tower saat arus petir disalurkan ke bumi melalui struktur tower: tahanan pembumian bersifat seri dengan impedansi surja dari tower, sehingga nilai tahanan pembumian makin tinggi akan menyebabkan kenaikan tegangan tower makin tinggi. Berdasarkan hasil simulasi, kenaikan tahanan pembumian tower menjadi 6 kali lipat menyebabkan kenaikan peluang BFOR hingga 129,93\% (Tabel 2). Berdasarkan sub bab 3.2, diketahui bahwa back flashover terjadi saat sambaran petir dengan nilai arus puncak -47 kA terjadi di kawat GSW (Gambar 7). Kontribusi kenaikan tegangan akibat nilai tahanan pembumian tower yang tinggi menyebabkan back flashover dapat terjadi untuk sambaran di kawat GSW dengan nilai arus puncak lebih rendah daripada -47 kA. Hal tersebut menyebabkan kenaikan probabilitas kejadian arus puncak petir yang menyebabkan kenaikan tegangan tower melebihi CFO dari insulator, sehingga nilai BFOR menjadi lebih tinggi. 
Tabel 2. Perbandingan outage rate untuk variasi nilai tahanan pembumian

\begin{tabular}{cccc}
\hline Parameter & $\begin{array}{c}\mathbf{R F} \\
\mathbf{( 5} \boldsymbol{\Omega})\end{array}$ & $\begin{array}{c}\mathbf{R F} \\
(\mathbf{2 0} \Omega)\end{array}$ & $\begin{array}{c}\mathbf{R F} \\
(\mathbf{3 0} \boldsymbol{\Omega})\end{array}$ \\
\hline SFFOR & 3,05 & 3,05 & 3,00 \\
BFOR & 12,75 & 17,45 & 33,33 \\
TOR & 15,80 & 20,50 & 36,33 \\
\hline
\end{tabular}

Berdasarkan panduan pemeliharaan SUTT di lingkungan PLN, nilai tahanan pembumian diukur secara berkala dengan menggunakan metode FoP seperti yang dinyatakan pada Gambar 8. Menurut IEEE, pengukuran nilai tahanan pembumian menggunakan metode FoP dilakukan pada elektroda pembumian yang telah dipisahkan daripada struktur yang dilindungi (IEEE Std 81 2012). Pada kondisi operasional, hampir sebagian besar tower SUTT memiliki elektroda pembumian yang dilas pada salah satu kaki tower untuk mencegah tindakan pencurian maupun tindakan vandalisme lainya. Hal tersebut berpotensi menghasilkan kesalahan pengukuran apabila tower SUTT tersebut diukur nilai tahanan pembumiannya dengan metode FoP. Untuk kondisi dimana tower SUTT tidak memiliki elektroda pembumian yang terpisah, IEEE menyatakan metode pengukuran menggunakan gabungan FoP dan pengukuran arus bocor seperti yang dinyatakan pada Gambar 9. Perbandingan hasil pengukuran tahanan pembumian menggunakan menggunakan metode FoP terhadap metode FoP dan pengukuran arus bocor dapat dilihat pada Tabel 3 .

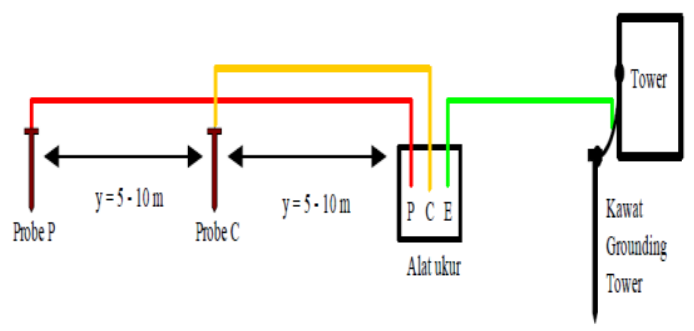

Gambar 8. Metode pengukuran tahanan pembumian dengan metode FoP

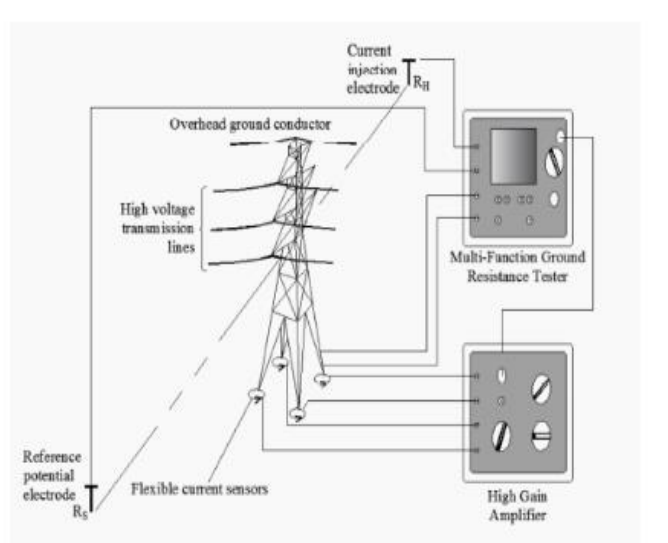

Gambar 9. Metode pengukuran tahanan pembumian dengan metode gabungan FoP dan pengukuran arus bocor
Tabel 3. Perbandingan hasil pengukuran tahanan pembumian tower

\begin{tabular}{ccc}
\hline Parameter & $\begin{array}{c}\text { Tahanan Pembumian Tower } \\
(\Omega)\end{array}$ \\
\cline { 2 - 3 } & FoP & $\begin{array}{c}\text { FoP dan } \\
\text { pengukuran arus } \\
\text { bocor }\end{array}$ \\
\hline 5 & 7,80 & 7,80 \\
10 & 2,94 & 3,97 \\
11 & 13,80 & 2,24 \\
13 & 10,52 & 4,19 \\
14 & 2,66 & 5,87 \\
18 & 1,74 & 2,42 \\
19 & 5,23 & 4,19 \\
20 & 7,89 & 27,86 \\
26 & 4,91 & 28,32 \\
27 & 1,74 & 2,61 \\
\hline
\end{tabular}

Berdasarkan hasil perbandingan pengukuran tahanan pembumian kaki tower dari SUTT yang memiliki ground rod tidak terpisah (Tabel 3), pengukuran FoP + pengukuran arus bocor menunjukkan bahwa sebagian tower memiliki nilai tahanan pembumian yang tinggi dibandingkan dengan hasil pengukuran menggunakan FoP. Hal tersebut dapat berpotensi menjadi hidden risk, dimana sambaran petir ke tower SUTT akan menyebabkan terjadinya back flashover oleh karena nilai tahanan pembumian yang tinggi.

\section{KESIMPULAN DAN SARAN}

Berdasarkan hasil evaluasi dan analisis data, diketahui kenaikan tahanan pembumian tower sebesar 6 kali dapat menyebabkan kenaikkan total outage rate dari saluran udara sebesar $129,93 \%$. Hal tersebut mendorong perlunya dilakukan pemantauan nilai tahanan pembumian secara teratur dengan menggunakan metode yang sesuai dengan standar yang berlaku. Khusus untuk tower dengan ground rod yang tidak dapat dipisahkan dari struktur tower, maka perlu dipertimbangkan pengukuran menggunakan metode FoP dan pengukuran arus bocor.

\section{DAFTAR PUSTAKA}

Ab Kadir, M. Z. A., J. Sardi, W. F. Wan Ahmad, H. Hizam, and J. Jasni. 2009. "Evaluation of a 132 KV Transmission Line Performance via Transient Modelling Approach." European Journal of Scientific Research 29(4):533-39.

Bhattarai, R., R. Rashedin, S. Venkatesan, A. Haddad, H. Griffiths, and N. Harid. 2008. "Lightning Performance of $275 \mathrm{KV}$ Transmission Lines." Proceedings of the Universities Power Engineering Conference. doi: 10.1109/UPEC.2008.4651622.

Committee, Distribution. 1997. IEEE Guide for Improving the Lightning Performance of Transmission Lines.

Cummins, Kenneth L., Jennifer G. Wilson, and Amy 
S. Eichenbaum. 2019. "The Impact of CloudTo-Ground Lightning Type on the Differences in Return Stroke Peak Current over Land and Ocean." IEEE Access 7:174774-81. doi: 10.1109/ACCESS.2019.2956685.

Filipe, Nuno, Carlos Cardoso, João Mendes, Andreia Leiria, David Duarte, Luis Perro, and M. Matos Fernandes. 2016. "A Methodology for Estimating Transmission Lines Lightning Performance Using a Statistical Approach." $201633 r d$ International Conference on Lightning Protection, ICLP 2016. doi: 10.1109/ICLP.2016.7791342.

Gillespie, J. A. Tony, and Glenn Stapleton. 2004. "Improving Double Circuit TransmissionLine Reliability Through Lightning Design." Cigre 2004 1-8.

Holle, Ronald, and William Brooks. 2019. "Vaisala 2018 Annual Lightning Report.” 14.

Holle, Ronald L., and Kenneth L. Cummins. 2010. "Monthly Distributions of U.S. Nldn Cloud-toGround Lightning." 21st International Lightning Detection Conference/21st International Lightning Meteorology Conference 13.

IEEE Std 81. 2012. IEEE Guide for Measuring Earth Resistivity, Ground Impedance, and Earth Surface Potentials of a Grounding System. Vol. 2012.

Jambak, M. I., Z. Nawawi, R. F. Kurnia, Z. Buntat, M. A. B. Sidik, Y. Z. Arief, A. A. Wahab, Z. Ramli, and M. E. Ramly. 2016. "Analysis of Transmission Lightning Arrester Locations Using Tflash." TELKOMNIKA (Telecommunication Computing Electronics and Control) 14(4):1228. doi: 10.12928/telkomnika.v14i4.3792.

Javor, Vesna, Leonid Stoimenov, Nikola Džaković, Nikola Dinkić, Dario Javor, and Hans Dieter Betz. 2018. "LINETGIS Analysis of Lightning Flash Density in Serbia Based on Ten Years Data." Serbian Journal of Electrical Engineering 15(2):201-11. doi: 10.2298/SJEE1802201J.

Martínez Velasco, Juan A., Javier Corea Araujo, and Samir Bedoui. 2018. "Lightning Performance Analysis of Transmission Lines Using the Monte Carlo Method and Parallel Computing." Ingeniare 26(3):398-409. doi: 10.4067/S071833052018000300398 .

Mikropoulos, P. N., and T. E. Tsovilis. 2012. "Estimation of the Shielding Performance of Overhead Transmission Lines: The Effects of Lightning Attachment Model and Lightning Crest Current Distribution." IEEE Transactions on Dielectrics and Electrical Insulation 19(6):2155-64. doi: 10.1109/TDEI.2012.6396976.

Mikropoulos, P. N., and T. E. Tsovilis. 2017.
"Lightning Interception Probability and Shielding Performance of Overhead Transmission Lines." 2010 30th International Conference on Lightning Protection, ICLP 2010 (July 2015). doi: 10.1109/ICLP.2010.7845912.

Nampak, Haleh, Peter Love, Paul Fox-Hughes, Christopher Watson, Jagannath Aryal, and Rebecca M. B. Harris. 2021. "Characterizing Spatial and Temporal Variability of Lightning Activity Associated with Wildfire over Tasmania, Australia." Fire 4(1):1-22. doi: 10.3390/fire4010010.

Shafaei, A., A. Gholami, and R. Shariatinasab. 2012. "Probabilistic Evaluation of Lightning Performance of Overhead Transmission Lines, Considering Non-Vertical Strokes." Scientia Iranica 19(3):812-19. doi: 10.1016/j.scient.2011.06.014.

Thottappillil, Rajeev, and Nelson Theethayiz. 2009. Protection against Lightning Surges. 